of nematode distribution, dispersal, habitats, groupings and communities, and population change. These include some interesting, but all too brief, discussions on the origins and recent past of nematodes, clustering, their means of dissemination, and some methods of analysing nematode communities and populations. It is well accepted that parasitic nematodes are always found associated with all forms of plant life; and, under the heading of habitats, the author mentions their associations with fungi, algae, lichens, mosses and higher plants. An introduction to population changes is presented in which seasonal changes, growth patterns, $r$ and $k$ selection, and sex ratios are discussed.

In the following two chapters the author deals with the soil environment: in the first of these, he discusses bas:c soil principles referring frequently to the interrelationships between soil factors; and in the second, he discusses the effects of physical and chemical soil changes on the nematodes, the section on effects of soil fertility is of particular interest to plant nematologists. The remainder of the book is concerned with survival, biological control, and interactions between nematodes and with other organisms. The final chapter is a disappointingly short account of the effects of agricultural practices on

\section{Search for psychological reality}

Linguistic Theory and Psychological Reality. By M. Halle, J. Bresnan and G. A. Miller. Pp.329. (MIT Press: Cambridge, Massachusetts, and London, 1978.) £12,25; \$17.50.

THE search for psychological reality is on again. Last time the psychologists did the searching with the new toys they did not understand; this time it is the linguists (at least in approach) who are doing the searching and get the reviewer very confused in the process. It is a book without Chomsky, but with his bust on the mantlepiece, in which we start with the acceptance that linguistics is a branch of psychology but come away with the feeling that they mean that psychology is a branch of linguistics. Linguists and psychologists talk together; they write chapters which refer to each other (good editorial work here) but to scarcely anyone else.

We start with a chapter by Bresnan on "A realistic transformational grammar". The largest part of this is devoted to a beautiful linguistic demonstration of how some facts which used to be handled by transformations nematode populations, although the author acknowledges that the influence of cultural practices on nematodes has not received the attention it deserves.

There are errors throughout the book which could have been avoidedfor example, the use of some defunct nematode nomenclature. Dr Norton has summarised much of the relevant literature in tabular form rather than discussing it in the text; even so these lists are not exhaustive. Most of the literature cited and the majority of the discussions relate to the ecology of nematodes in the United States. Although these are often relevant to work elsewhere, the book seems to have been written with the North American market in mind.

It is a useful introductory book to plant nematode ecology in which the author has brought together information from ecological disciplines relating to nematodes under one cover. Some interesting ideas are introduced, but it is not a sufficiently in-depth, critical or comprehensive study of the subject to entirely satisfy the needs of the professional nematologist.

John Bridge

John Bridge is Overseas Plant Nematology Liaison Officer for the Ministry of Overseas Development and a Research Fellow at Imperial College, University of London, UK.

are now handled in the lexicon. The linguistics is generally judged among the best being produced currently and is very convincing. The 'realistic' in the title is introduced early. She makes the explicit claim that if a grammar is "to represent the knowledge of the language user in any psychologically interesting way" then all the grammatical rules must be realisable in a psychological model. If this is a serious claim then one might think that the best strategy would be to focus first on the types of constraint that psychology might impose Instead we get the impression that the psychology is an afterthought. A hand reaches out languidly to pluck out a single piece of supporting data or intuition but no more. Thus Bresnan gives us reasons for arriving at passive and short passive forms directly instead of by means of transformations. At the end she notes that one of the other contributors to the volume reports that short passives (for example. the dog was bitten) was acquired before full passives by children. The tone of voice is almost congratulatory-how sensible of the children to realise the correct derivation! Such use of psychological evidence permeates the book.

Wanner and Maratsos give an example of a different kind of model, an Augmented Transition Network
(ATN). One of their aims is to parse sentences without recourse to transformations. Strangely, then, we are also told several times that these parsers "are not incompatible with a transformational model of language". Remembering that Bresnan still found transformations necessary, this is re assurring. However, if Brenan's grammar is psychologically realistic and the ATN's have psychological reality doesn't the latter have to be the realisation of the former?

The lexical side of language is nc better handled except in a little piece on "The child as a word learner" by Susan Carey. In this she exposes the magnitude of the task of pairing thousands of words with their meanings in a few years. No answers, but a hint of the psychological questions. George Miller has a chapter on the semantic relations among words. This is a development of the ideas he put forward with Johnson-Laird in Language and Perception (reviewed in Nature; 264, 124, 1976). Miller makes some tight formal points but his thinking doesn't make as close a contact with psychological issues as the earlier work. Still, this is better than Jackendorf who, like Miller, wants to claim that semantics must derive from a general theory of conceptual structures. This seems a saner view of universality than one which bases it exclusively on language, but Jackendorf effectively turns the relationship around by using linguistic analysis to derive the semantic system from which the cognitive universals should emerge. The effectiveness of his argument may be judged from a nonlinguistic parallel which he describes"the ability of a dancer to create appropriate dances for given music . . in such a way that there is substantial interpersonal agreement on how appropriate the translation is." There must be generalisations which mediate the "complex and subtle" expression "determined at least in part along lines laid down by the nature of the organism." (Q.E.D.).

This kind of nativism gets another airing by Halle in a discussion of phonology where a 1971 result of Eimas is cited in support of innate mechanisms of speech analysis. Half-a-dozen or more recent refutations of this view have apparently gone unremarked (see, for example a chapter by Mehler in Psycholinguistics, series 2, ed. Morton and Marshall; Elek, 1979). There is a lot of intelligence in this book overall and a review by a linguist might give a much more positive impression but the and in the title is disjunctive.

John Morton

John Morton is on the scientific staff at the MRC Applied Psychology Unit, Cambridge, UK. 